BMJ Open

Diabetes

Research

\& Care

\title{
Diabetes, driving and fasting during Ramadan: the interplay between secular and religious law
}

\author{
Nazim Ghouri, ${ }^{1}$ Sufyan Hussain, ${ }^{2,3}$ Ruzwan Mohammed, ${ }^{4}$ Salem Arifi Beshyah, ${ }^{5}$ \\ Tahseen A Chowdhury, ${ }^{6}$ Naveed Sattar, ${ }^{1}$ Aziz Sheikh ${ }^{7}$
}

To cite: Ghouri N, Hussain S, Mohammed R, et al. Diabetes, driving and fasting during Ramadan: the interplay between secular and religious law. BMJ Open Diab Res Care 2018;6:e00520. doi:10.1136/ bmjdrc-2018-000520

Received 30 January 2018 Accepted 25 April 2018

\section{Check for updates}

${ }^{1}$ University of Glasgow, Institute of Cardiovascular and Medical Sciences, Glasgow, UK ${ }^{2}$ Department of Diabetes and Endocrinology, Guy's and St Thomas' NHS Foundation Trust, London, UK

${ }^{3}$ Department of

Diabetes, Endocrinology and Metabolism, Imperial College London, London, UK

${ }^{4}$ Solas Foundation, Glasgow, UK ${ }^{5}$ Institute of Medicine, Sheikh Khalifa Medical City, Abu Dhabi, United Arab Emirates

${ }^{6}$ Department of Diabetes and Metabolism, Barts Health NHS Trust, London, UK

${ }^{7}$ Usher Institute of Population Health Sciences and Informatics, University of Edinburgh, Edinburgh, UK

Correspondence to Dr Nazim Ghouri;

nazim.ghouri@glasgow.ac.uk

\section{ABSTRACT}

A large proportion of the Muslim population fasts during Ramadan. The risk of hypoglycemia is increased with fasting during Ramadan in people with diabetes who are on insulin and insulin secretagogues. Therefore, the combination of fasting with diabetes and driving presents a challenging situation, with legal implications for such individuals and their healthcare professionals. This novel, narrative, non-systematic review discusses the importance of addressing hypoglycemia in fasting with reference to secular legal guidance on driving with diabetes. We discuss religious aspects relating to fasting and driving in Islam. While there is no clear guidance or legal position on diabetes and driving for individuals who are fasting, Islamic law provides a logical framework to address this. Healthcare professionals need to raise and facilitate discussions on this often-overlooked topic with people with diabetes who are planning on fasting to minimize the potential for public harm. For some individuals fasting perhaps should be avoided when driving and that this religiously compatible position would best be adopted when one is dependent on driving for livelihood. Ultimately further research on glycemic control and management when fasting and driving, as well as a formal legal guidance on this topic, is required to safeguard healthcare professionals and the public from the potential dangers of driving with diabetes and fasting.

\section{INTRODUCTION}

Muslims see fasting as a cardinal religious obligation. An estimated 93\% of Muslims globally fast during the month of Ramadan. ${ }^{12}$ Ramadan fasting entails complete abstinence from food and drink from dawn to sunset. In recent years, guidance for healthcare professionals has been produced to support diabetes management of Muslims who wish to fast during the month of Ramadan. ${ }^{3-8}$ Hypoglycemia is a recognized risk associated with fasting in individuals taking insulin and/or sulfonylureas ${ }^{410}$ and is likely to be increased in those living in temperate regions where fasting can fall in the long summer months. ${ }^{4}$ Further, while the most recent international guidance takes into consideration social and work-related aspects, the topic of road vehicle driving has not been addressed. ${ }^{4}$

The effects of fasting, particularly when prolonged, on social and occupational issues, such as driving, is underappreciated. Driving poses a unique consideration for those who fast, due to the glycemic parameters that need to be met for safety reasons. Driving during Ramadan is associated with an increased risk of sleep-related road traffic accidents. ${ }^{11}$ Many who fast wake or stay awake for the predawn meal and for additional voluntary prayers. Extra care is needed by those with diabetes to avoid increasing the risk of sleep-related traffic accidents during Ramadan. Healthcare professionals should consider asking Muslims with diabetes about their intentions to fast during Ramadan so that they may be able to provide appropriate advice about fasting. It should be recognized that a significant number of people who have been advised not to fast by their healthcare professionals may still choose to do so. ${ }^{9}$ However, as the decision to drive may pose risk to the person and other road users, healthcare professionals have a responsibility to minimize this risk.

The importance of discussing diabetes management that is specific to Ramadan does lead to favorable outcomes-in one recent large multinational observational study, people with diabetes who received Ramadan-specific information did better at following Ramadan-specific diabetes management recommendations, including blood glucose monitoring during Ramadan, appropriately altering drug dosage and timings before Ramadan, checking blood glucose, and importantly breaking the fast on the development of symptoms of hypoglycemia or hyperglycemia. ${ }^{12}$ Further, very recent qualitative data suggest that while Muslims are optimistic about their well-being when fasting during Ramadan, many choose to fulfill their religious obligation despite being 
discouraged by their doctors. ${ }^{13}$ The authors concluded that collaboration with religious authorities should be explored to ensure patients receive adequate education before fasting during Ramadan.

This is a complex area as healthcare professionals and people with diabetes who would like to fast need to consider relevant local secular legislation and Islamic legislation on this subject. The aim of this review is to raise awareness and provide insights and guidance for healthcare professionals in managing those Muslims who express an interest or intention to undertake fasting during Ramadan. We seek to summarize these bodies of knowledge and rulings with practical guidance (using the UK and its associated secular legislation as an exemplar model). We hope this will help inform day-to-day decision making in a way that is sensitive to the needs of their Muslim patients. ${ }^{14}$

\section{METHODS}

This is a thematic, narrative, non-systematic review with a view to exploring the points of agreements and differences between secular law based on British law and the Shari'ah Islamic law as they apply to the risk assessment of Muslim people who are driving during the day of Ramadan. A search of the literature was done using online databases (PubMed, Google Scholar) with the following search terms in various combinations: driving, Ramadan fasting, and hypoglycaemia. Relevant records were retrieved and reviewed primarily by $\mathrm{NG}$ and $\mathrm{SH}$, but with additional contribution from all authors. Recent Ramadan management guidelines, current official British and European driving rules, and the relevant sections of Islamic texts were reviewed too. Figure 1 highlights the absence of published data on PubMed in relation to diabetes, driving and Ramadan over a 10-year period. The article aimed to discuss the Ramadan fasting rulings, present the secular fasting rules, attempt to develop a model for driving during fasting based on similar risk

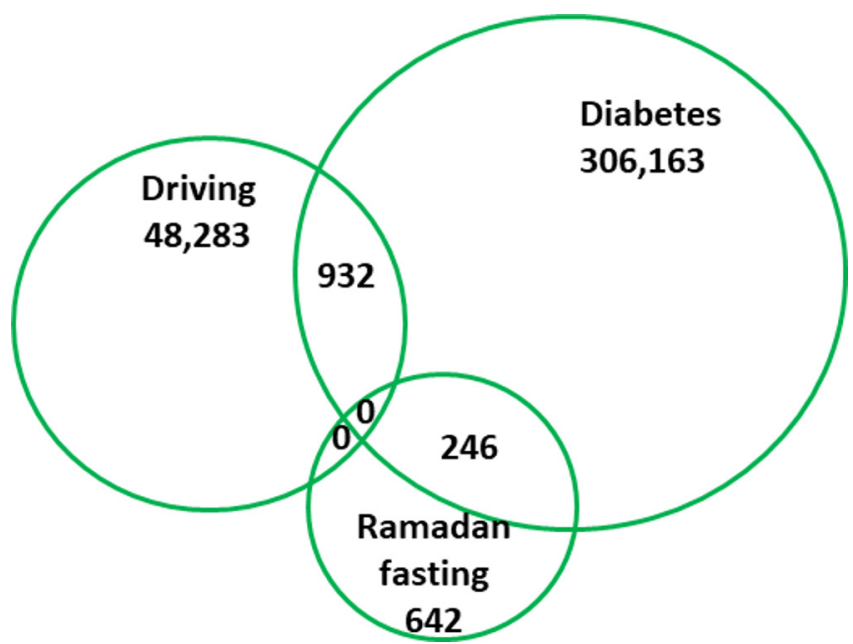

Figure 1 Conceptual tripartite model for the limited coverage on the interplay between diabetes, driving and Ramadan fasting over 10 years on PubMed online database. Sizes are schematic and are not in correct scale. states, resolve any differences or conflicts between secular and religious laws, and finally recommend a working practical plan in advising the fasting driver. The initial draft was developed and further developed by the rest of the authors via several rounds of multilateral electronic communications. All authors approved the final version.

\section{HYPOGLYCEMIA, DRIVING AND LICENSING STANDARDS}

Hypoglycemia leads to a decline in neurocognitive function and impairment in judgment and complex task handling. ${ }^{15} 16$ Driving standards in the UK in relation to diabetes are defined by the Driver and Vehicle Licensing Agency (DVLA), ${ }^{17}$ and are largely based on the European Commission Directive $(2006 / 126 / \mathrm{EC})^{18}$ and the 2009/113/EC Amending Annex III to Directive 2006/126/EC, ${ }^{19}$ the overarching legal guidance for European Union (EU) member states. Details of restrictions in relation to hypoglycemia in the above directives are summarized in table 1 . In response to submissions to relax licensing restrictions, some of these have been amended recently in Directive 2016/1106/EC ${ }^{20}$ and were implemented in the UK in January 2018. ${ }^{17}$ The latest EU Directive has advocated specific relaxation of some licensing regulations for drivers of group 1 vehicles. The key changes were reviewed recently by Graveling and Frier. ${ }^{21}$ These changes include stating 'inadequate awareness' rather than 'impaired' hypoglycemia, reduction in the length of time of revocation of a driving license from 12 to 3 months, and restricting the relevance of severe hypoglycemia to waking hours. ${ }^{21}$ Globally, there is a wide variation between different countries and regions in the statutory requirements and policies used to regulate and assess drivers with diabetes. ${ }^{22}$

\section{INSULIN-TREATED DIABETES AND DRIVING}

In the UK, the DVLA details comprehensive recommendations and requirements for group 1 (car and motorcycle) and group 2 (bus and lorry) drivers who are treated with insulin, and these are summarized in table $2 .{ }^{172324}$ It is noteworthy that modern insulin analogs are potentially safer and have been shown to carry a lower risk of hypoglycemia during fasting. ${ }^{25}$ Previous research demonstrates that there is delayed recovery of neurocognitive function following hypoglycemic episodes, giving a strong biomedical basis for this advice. ${ }^{26} 27$ The guidance also advocates that "particular care should be taken during changes of insulin regimens, change of lifestyle, exercise, travel and pregnancy'. ${ }^{17}$ Such details are currently not included in the European Commission Directive, with individual countries having their own standards and recommendations. In a recent international study, no restrictions on drivers with insulin-treated diabetes existed in 59 out of 82 surveyed countries $(69.4 \%) .{ }^{22}$ Lack of restrictions on licenses in drivers on insulin was evident in less developed countries, indicated by geographic basis and by using an established national social/political/economic index (gross domestic product). ${ }^{22}$ 
Table 1 Driving and hypoglycemia: driving standards for people with diabetes per the DVLA licensing standards and the European Commission Directive (2006/126/EC and Amending Directive 2009/113/EC) $)^{17-19}$

\begin{tabular}{|c|c|c|}
\hline & European directive & DVLA \\
\hline \multirow[t]{3}{*}{ Group 1 license } & Must not have recurrent severe hypoglycemia. & $\begin{array}{l}\text { No more than } 1 \text { episode of severe hypoglycemia while } \\
\text { awake in the preceding } 12 \text { months or the most recent } \\
\text { episode occurred more than } 3 \text { months ago. }\end{array}$ \\
\hline & $\begin{array}{l}\text { Must not have impaired awareness of } \\
\text { hypoglycemia. }\end{array}$ & Adequate awareness of hypoglycemia. \\
\hline & $\begin{array}{l}\text { Understanding of the risk of hypoglycemia } \\
\text { and adequate control of the condition. }\end{array}$ & Not regarded as likely risk to public while driving. \\
\hline \multirow[t]{5}{*}{ Group 2 license } & Full hypoglycemic awareness. & Full awareness of hypoglycemia. \\
\hline & $\begin{array}{l}\text { No severe hypoglycemic events in the } \\
\text { previous } 12 \text { months. }\end{array}$ & $\begin{array}{l}\text { No episode of severe hypoglycemia in the preceding } 12 \\
\text { months. }\end{array}$ \\
\hline & $\begin{array}{l}\text { Adequate control of the condition } \\
\text { (demonstrate regular blood glucose } \\
\text { monitoring, at least twice daily and at times } \\
\text { relevant to driving). }\end{array}$ & \\
\hline & Understanding of risks of hypoglycemia. & \\
\hline & No other debarring complications of diabetes. & \\
\hline $\begin{array}{l}\text { Severe hypoglycemic } \\
\text { event reporting (all } \\
\text { categories) }\end{array}$ & $\begin{array}{l}\text { During waking hours, event unrelated to } \\
\text { driving should be reported and give rise to } \\
\text { reassessment of licensing status. }\end{array}$ & $\begin{array}{l}\text { Following a recent update, current UK severe } \\
\text { hypoglycemia event reporting is similar to EU for group } \\
1 \text { licenses (severe hypoglycemia while awake). }\end{array}$ \\
\hline
\end{tabular}

DVLA, Driver and Vehicle Licensing Agency; EU, European Union.

\section{IMPLICATIONS FOR DRIVING AND FASTING FOR PEOPLE WITH DIABETES ON INSULIN AND TABLETS CARRYING A HYPOGLYCEMIC RISK}

Fasting during Ramadan with insulin-treated and secretagogue-treated diabetes constitutes a significant change in lifestyle and presents an increased risk of hypoglycemia. This requires particular care when driving. Current DVLA guidance, European Commission Directive on driving licenses, and Ramadan and diabetes guidelines do not specifically address the issue of driving and fasting with

Table 2 DVLA recommendations and requirements for diabetes treated with insulin 172324

\begin{tabular}{|c|c|c|}
\hline Treatment & License & Guidance \\
\hline \multirow[t]{4}{*}{ Insulin-treated diabetes } & \multirow[t]{4}{*}{ Groups 1 and 2} & $\begin{array}{l}\text { 'Blood glucose testing no more than } 2 \text { hours before the start of the first } \\
\text { journey' and 'every } 2 \text { hours fwhile driving'. }\end{array}$ \\
\hline & & $\begin{array}{l}\text { 'if your blood glucose is } 5.0 \mathrm{mmol} / \mathrm{L} \text { or less, take a snack. If it is less than } \\
4.0 \mathrm{mmol} / \mathrm{L} \text { or you feel hypoglycaemic do not drive'. }\end{array}$ \\
\hline & & $\begin{array}{l}\text { 'must not start driving again until } 45 \text { min after the blood glucose has } \\
\text { returned to normal'. }\end{array}$ \\
\hline & & $\begin{array}{l}\text { 'particular care should be taken during changes of insulin regimens, } \\
\text { change of lifestyle, exercise, travel and pregnancy'. }\end{array}$ \\
\hline \multirow[t]{2}{*}{$\begin{array}{l}\text { Oral hypoglycemic agents (eg, } \\
\text { insulin secretagogues such as } \\
\text { sulfonylureas and glinides) }\end{array}$} & Group 1 & $\begin{array}{l}\text { Do not need to notify DVLA provided: } \\
\text { 'no more than one episode of severe hypoglycaemia in the last } 12 \\
\text { month } \\
\text { if needed, detection of hypoglycaemia is by appropriate blood glucose } \\
\text { monitoring at times relevant to driving and clinical factors, including } \\
\text { frequency of driving } \\
\text { under regular review'. }\end{array}$ \\
\hline & Group 2 & $\begin{array}{l}\text { 'regular self-monitoring of blood glucose - at least twice daily and at } \\
\text { times relevant to driving i.e. no more than } 2 \text { hours before the start of the } \\
\text { first journey and every } 2 \text { hours while driving'. }\end{array}$ \\
\hline $\begin{array}{l}\text { Diabetes managed by other } \\
\text { medication (including non- } \\
\text { insulin injectables) }\end{array}$ & Groups 1 and 2 & $\begin{array}{l}\text { No specific notification and monitoring requirements have been provided } \\
\text { and only general requirements apply. }\end{array}$ \\
\hline
\end{tabular}

DVLA, Driver and VehicleLicensing Agency. 
insulin-treated or secretagogue-treated diabetes during Ramadan. From a biomedical perspective, the twofold to sevenfold increase in risk of hypoglycemia with diabetes and fasting ${ }^{910}$ requires strict adherence to DVLA precautions if driving.

\section{RELIGIOUS CONSIDERATIONS ON MATTERS SPECIFICALLY RELATING TO FASTING AND SECULAR LEGAL ASPECTS OF DRIVING FOR MUSLIMS INTENDING TO FAST}

Current thinking highlights situations in which people with diabetes may be exempted from fasting, particularly when it comes to longer fasts, and is derived directly from the Qur'an, the holy book of Muslims. ${ }^{14} 7$ The guidance explicitly states that Islam permits, and indeed supports, those with appropriate ailments to be exempted from fasting. ${ }^{1}$ In such situations, non-fasting Muslims have two main options:

1. Making up the missed fast when health permits them to do so-either when the illness is no longer present, such as an acute illness, or when the illness is not worsened by fasting at another point in time in relation to chronic illness.

2. A perpetual exemption from fasting in those whose illness will not permit them to keeping fasts indefinitely, this being replaced by a requirement to feed the poor, known as 'Fidyah'. Even after considering the aforementioned general Islamic principles, there may be a need for healthcare professionals or people with diabetes to explore further considerations when deciding if fasting is appropriate, or indeed to maintain the fast once started, if mitigating circumstances arise.

Within religious traditions, the process of developing cardinal religious virtues, such as patience and servitude to God, requires a devotee to undertake certain practices that will entail varying degrees of difficulty in order to effect a desired change in habits perceived as detrimental to the human soul. However, the Islamic tradition explicitly recognizes the danger that, for certain people, this will lead to not just normal difficulty, but perceptible harm or damage. In light of this, Islamic law, otherwise known as Shari'ah, seeks to pre-empt the onset of harm to the individual by providing guidelines that allow a person to take a dispensation to opt out of certain practices, either for a short period of time or indefinitely. If it is established, however, that this will lead to an observable onset or worsening of an illness that limits normal human functions, this emphasizes prioritizing one's health over fasting. ${ }^{26}$

The Shari'ah also recognizes the secular legal requirements of public good, that is, care or safety for others, for example, other road users. As these are based on current understandings of risk, it would not be permitted to encroach on such restrictions by attempting or continuing to fast because of the general legal maxim that 'harm is to be alleviated' ${ }^{27}$ Ultimately, however, the final decision to fast or not rests with the individual, and they have the right to fast even if the medical or religious opinion states otherwise. This does not, however, absolve the person from their personal and civic responsibilities in terms of maintaining their health appropriately, in terms of medical fitness to drive.

In the Shari'ah, exemptions or dispensations are applied when a necessity (dhurura) or need (haajat) arises. ${ }^{28}{ }^{29}$ It is worthwhile appreciating these two terms used when it comes to classifying situations that may arise. A 'necessity' arises when a person needs to break the Shari'ah due to dire circumstances to directly safeguard one of the essential benefits of Shari'ah (ie, religion, life, intellect, lineage or property/wealth). In this situation, the person acts in a manner that is otherwise unlawful to secure existence. 'Needs' are subordinate to necessities and are things, often of a personal nature, deemed to be of importance because they remove severity and hardship in day-to-day life in relation to promoting and protecting the essential benefits. For example, a healthy person would not be permitted to break a fast except in a situation where there is a more pronounced hardship to their fast than is normally to be experienced, such that it impairs their capacity to work safely. Therefore, a need for one person may not be a need for another as circumstances may vary. If an individual has been stratified as having high risk or very high risk of harm from fasting due to their diabetes, then from this perspective alone, there is sufficient reasoning for them not to fast because of the magnitude of risk of personal harm. ${ }^{14}$

\section{POTENTIAL INTERPLAY BETWEEN SHARI'AH AND SECULAR LAWS-CONSIDERATIONS FOR THE HEALTHCARE PROFESSIONAL AND PATIENT (USING UK DRIVING LEGISLATION AS AN EXAMPLE)}

The Shari'ah therefore includes a concept of driving being undertaken owing to a necessity, need or choice. This contrasts with national laws and guidelines, as no national guideline or law makes any distinction based on the purpose for which driving is undertaken. However, the underlying reason for driving may make reaching a decision easier especially when a person with diabetes is already stratified as having higher risk of harm from fasting. Resolving such contemporary incidents cannot be based on literal interpretation but rather by analogy similar to the exemption of those who have obligations to undertake hard types of physical labor included in the 2009 Fatwa by the International Fiqh Academy and incorporated in recent risk stratifications. ${ }^{14}$

If a healthcare professional advises that it is safe for a person with diabetes to fast, or if the person with diabetes chooses to fast despite contrary advice, the following scenarios (listed in Box 1) should also be considered to help guide both parties when deciding: (1) how the act of driving is viewed under the Shari'ah law; and (2) what, if any, advice is needed to maintain safety, including driving cessation. In all circumstances local legislation must be followed. 
Box 1 Potential interplay between Islamic law (Shari'ah) and secular laws

Is driving being undertaken owing to a necessity, need or choice?

What if a person with diabetes who is fasting develops symptoms of hypoglycemia or is found to have a blood glucose $<4 \mathrm{mmol} / \mathrm{L}$ ?

- What about for subsequent fasts-does a person need to experience a minimum number of hypoglycemic episodes before it is deemed inappropriate for a person to fast when they need to drive?

-What if there is a low probability that a person with diabetes will develop blood glucose levels not legally compatible with driving, and there is a need to drive?

What if a person with diabetes has a blood glucose between 4 and $5 \mathrm{mmol} / \mathrm{L}$ and there is a need to drive?

-What if a person chooses to drive and has to stop driving because of symptoms or blood glucose readings?

$\checkmark$ Are there any special considerations for individuals exercising group 2 license privileges (eg, buses, heavy goods vehicles) taking insulin or insulin secretagogues?

-What are the ramifications if a person chooses to drive despite not being allowed to drive or strongly advised not to do so?

\section{Is driving being undertaken owing to a necessity, need or} choice?

- While no person 'needs to drive' as it is not essential to life, driving should ordinarily be seen as an option. However, a person may be in a situation where they rely on driving as part of their job, and if by forfeiting the job they may find difficulty in finding alternative employment, or driving at a time of non-fasting hours such that it jeopardizes the undertaking of essential obligations/needs, such as providing maintenance for dependents, housing and food (including essential shopping). Such an individual would be permitted to remain in such employment and alter one's fasting regimen if required, that is, being unable to keep fasting because legal requirements cannot be met, thus making up fasts during the rest of the year at times which would not impinge on the original mitigating circumstances or paying the Fidyah. ${ }^{30}$

- In the context of having adequate transportation as an important factor for well-being and social inclusion, from a Shari'ah perspective this would not ordinarily be seen as a factor that qualifies for an exemption to fast. However, if an individual was experiencing a severe mental illness, for where socializing was essential therapeutically based on the opinion of a qualified physician, then a person could be exempted from fasting if driving was the only means available for transportation for such treatment, based on the legal maxim used in circumstances of necessity 'hardship begets ease'. ${ }^{31}$

- An individual would be expected to explore all reasonable alternatives, for example, use of annual leave, and shortening or changing timings of work hours, if there is a reasonable expectation that hypoglycemia may compromise safe/legal driving. A reasonable expectation would be determined by applying one of the three following criteria: (1) prior experience of what fasting does to the ailment; (2) common knowledge (eg, a person with Addison's disease who does not take their hydrocortisone tables); and (3) the opinion of a qualified physician on the matter. ${ }^{32}$

\section{What if a person with diabetes who is fasting develops} symptoms of hypoglycemia or is found to have a blood glucose $<4$ mmol/L?

- The person should pre-empt adverse health issues by following any standard guidance and break their fast. ${ }^{4}$ In addition, they should be mindful of whether they have breached local guidelines on fitness to drive, for example, the strictures on severe hypoglycemic events (requiring the assistance of another person) and driving in the UK. ${ }^{33}$

What about for subsequent fasts—-does a person need to experience a minimum number of hypoglycemic episodes before it is deemed inappropriate for a person to fast when they need to drive?

- The Shari'ah provides grounds where a person may stop fasting for the rest of the month if hypoglycemic episodes have occurred previously, and there is an expectation that these may reasonably be expected to reoccur. $^{4}$

- The need for a type of employment that requires them to undertake driving would be sufficient grounds to permit the delay of fasting to a future time.

- A person who is told of an irreversible condition (due to health) not allowing them to fast will, as noted above, need to pay Fidyah-an expiation for missed days (donating food or money to a poor person for each day not fasted according to the teaching of the Holy Qur'an (Sur 2; Verse 184)). ${ }^{1}$

What if there is a low probability that a person with diabetes will develop blood glucose levels not legally compatible with driving, and there is a need to drive?

- A person with diabetes would start each fast normally and would break the fast, if needed, making up the fast at a later date. This is based on the guidance given to a healthy person undertaking heavy labor under adverse weather conditions. ${ }^{1}$ In normal situations, they should start fasting and break it if physical circumstances necessitate this.

- If it becomes apparent that a pattern is evolving, then the dispensation in the previous scenario would apply. ${ }^{1}$

What if a person with diabetes has a blood glucose between 4 and $5 \mathrm{mmol} / \mathrm{L}$ and there is a need to drive?

- The individual would be in the same situation as if the glucose was $<4 \mathrm{mmol} / \mathrm{L}$ and therefore would need to follow the standard DVLA guidance and required to eat before driving. 
What if a person chooses to drive and has to stop driving because of symptoms or blood glucose readings?

- Out of necessity the person would have to stop driving and make alternative transport arrangements. If this was not feasible, then one would break the fast as outlined above.

\section{Are there any special considerations for individuals}

exercising group 2 license privileges (eg, buses, heavy goods vehicles) taking insulin or insulin secretagogues?

- The important role of public transport in the society, and the primary duty of care and responsibility associated with driving a bus, coupled with increased harm that can result from accidents when driving such a vehicle, would permit and indeed advocate not fasting from the outset. ${ }^{26}$

- The Shari'ah is not expected to elaborate specific rulings on certain types of vehicles such as heavy goods vehicles; however, the various ancillary principles that have been discussed provide ample guidance and reasoning to permit not fasting when driving supported by experts. This is inferred from the hard work involved, the long distances traveled and the extreme danger to persons and properties involved in heavy goods vehicle accidents. Together these factors make one take a relativist rather than an absolutist approach to resolve the matter.

\section{What are the ramifications if a person chooses to drive} despite not being allowed to drive or strongly advised not to do so?

- The ramifications are based on considerations on personal welfare and duty of care for others. ${ }^{27}$ Any individual taking insulin who informs the DVLA signs an agreement which includes a statement that they will 'comply with the directions of the doctors treating my diabetes'. ${ }^{22}$ Such a written contract, both in Islamic law and in the UK, can result in prosecution if it transpires that a mishap has occurred as a result of neglecting any relevant advice given by the healthcare professional.

- In the context of driving by a fasting individual during Ramadan, the same level of commitment to the contract is required. Seeking professionals' advice, attending an educational program, altering doses and timing of diabetic drugs, and undertaking regular glucose monitoring have all been shown to reduce acute complications during Ramadan. ${ }^{11}$

A person with diabetes may wish to try undertaking trial (voluntary) fasts in the month preceding Ramadan as these experiences could provide useful evidence to support decision making during Ramadan. This practice has been suggested in the most recent international guidance and has been adopted by several of the authors of this paper, particularly in recent years as the fasts have become longer. ${ }^{4}$ Table 3 and figure 2 can serve as a useful patient-centered guide for healthcare professionals when discussing fasting with people with diabetes, incorporating

Table 3 Suggested pathway for discussions between healthcare professionals and people with diabetes intending to drive and fast during Ramadan (adapted from Beshyah et $\left.a\right|^{34}$ )

Before

Ramadan:

(evaluate and advise)

During

Ramadan: (monitor)

(monitor)

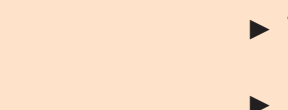

must do them).

- Always keep hypo treatments to hand in the car (even when you are fasting). 'if your blood glucose is $5.0 \mathrm{mmol} / \mathrm{L}$ or less, take a snack. If it is less than 4.0 $\mathrm{mmol} / \mathrm{L}$ or you feel hypoglycaemic do not drive'.

- Never ignore your hypo warning signs (eg, hunger, sweating, feeling faint and so on).

- If you have a hypo while driving, stop the vehicle as soon as possible, switch off the engine, remove the keys from the ignition and move from the driver's seat, take some fastacting carbohydrate, such as glucose tablets or sweets, and some form of longer acting carbohydrate, and do not start driving until 45 min after blood glucose has returned to normal.

- Manage hypoglycemia promptly and err on a wide safety margin.

- If in doubt, suggest stopping either fasting or driving depending on the relative risk assessment and demands of the circumstances.

After Ramadan: Review the patient in clinic or surgery (review)

within 2-4 weeks after Ramadan.

- Appraise the experiences and outcomes.

- Review the risk to benefit ratio of strategy adopted during Ramadan on an individual basis.

- Review the diabetes therapeutic strategy.

- Consider any ensuing legal implications.

and highlighting the importance of pre-Ramadan and post-Ramadan review, risk stratification, driving guidance and emphasis on documenting outcomes of such discussions. ${ }^{34}$ In all cases, healthcare professionals should not overlook their patients' words and driving habits (if 


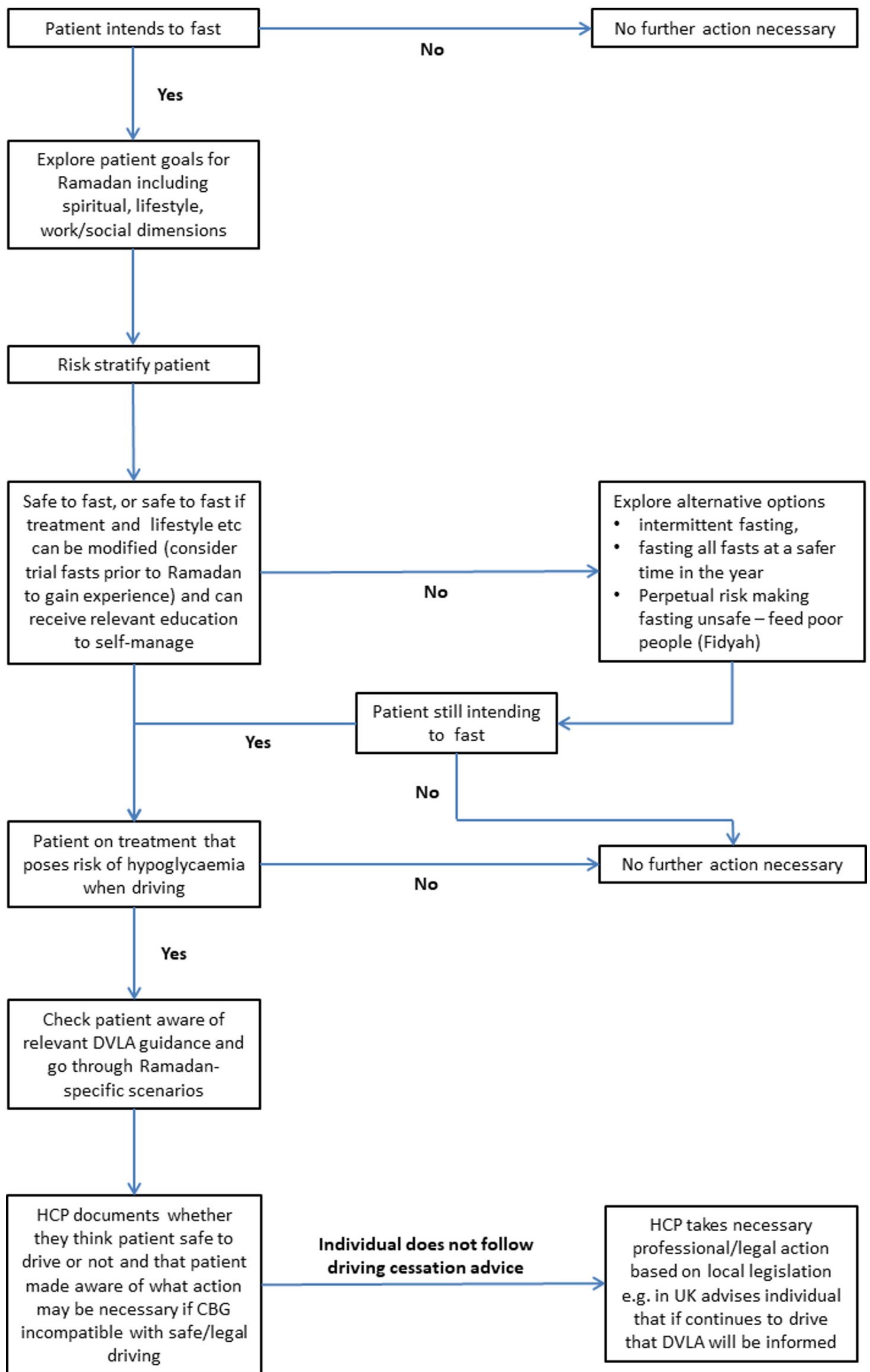

Figure 2 Suggested pathway for discussions between healthcare professionals and people with diabetes intending to fast during Ramadan. CBG, capillary blood glucose; DVLA, Driver and Vehicle Licensing Agency; HCP, health care professional. 
they become known) if they are compromising driving standards. Although professionally challenging to many healthcare professionals, if there is a need to report an individual to the driving authority, then this should be undertaken in the standard manner.

As with all doctor-patient encounters involving religious beliefs and practices, discussion of Ramadan fasting is not complete without a bioethical consideration despite the claimed differences between Western and Islamic ethics. ${ }^{35}$ All the Georgetown mantra principles of bioethics apply very well to this situation. For instance, physicians have to respect autonomy of the patients and his/her choice of observing the fast. However, 'non-maleficence' is manifested in the physicians' knowledge and application of the conditions and when people are exempted temporarily or permanently and avoidance of any harm to himself and other road users. Individuals with diabetes who are not classed at the higher risk categories who strictly observe Ramadan fasting may benefit in terms of weight reduction and quitting smoking (beneficence). Finally, 'justice' will be seen by balancing between the individual's right to observe Ramadan fasts and the right to public safety, with the scenarios discussed providing solutions which do not lead to the need to prioritize one individual over the public.

\section{CONCLUSIONS}

The tetrad of diabetes, fasting during Ramadan, hypoglycemia and safe driving stimulates a challenging discussion with potential legal ramifications. Islamic law provides logical and practical framework to facilitate the decision-making process through the concepts of necessities and needs, and the healthcare professional may benefit in using the suggestions discussed when raising and facilitating discussion with people with diabetes on fasting in the context of safeguarding health. Given that for many Muslims fasting is an important part of their individual life as well as in engendering community spirit and bonding, healthcare professionals should continue to adopt a patient-centered approach when engaging in discussion, asking their patients about their goals, and touching on the spiritual, emotional, clinical, physical, social and legal aspects, such as driving when planning on fasting for the month.

Thus, it is hoped that over time as healthcare professionals, people with diabetes and influential community members such as Imams become more aware of the evolving and dynamic issues, coupled with research that generates key relevant outcomes, stakeholders' dialogue on this topic and further guidance come out in a timely manner. Finally, this may also require the need for legal and authoritative bodies to work with such parties in providing clear and explicit guidance for people with diabetes, but in a sensitive and relevant manner. The roles of Imams, in particular in the dissemination of evolving guidance, will be key to reaching Muslims who give the highest importance to fulfilling their religious obligations. The issue of driving and Ramadan is a matter of relevance for any country that has secular legislation on driving and diabetes, as well for public safety; therefore, healthcare professionals in these countries must also consider having such discussions with people with diabetes.

Contributors NG conceived the idea. NG, SH, RM SAB and TC drafted the original manuscript. All authors critically revised the manuscript and approved the final version.

Funding The authors have not declared a specific grant for this research from any funding agency in the public, commercial or not-for-profit sectors.

Competing interests None declared.

Patient consent Not required.

Provenance and peer review Not commissioned; externally peer reviewed. Data sharing statement Data sharing is not applicable to this article as no new data were created or analyzed in this study.

Open Access This is an Open Access article distributed in accordance with the Creative Commons Attribution Non Commercial (CC BY-NC 4.0) license, which permits others to distribute, remix, adapt, build upon this work non-commercially, and license their derivative works on different terms, provided the original work is properly cited and the use is non-commercial. See: http://creativecommons.org/ licenses/by-nc/4.0/

(C) Article author(s) (or their employer(s) unless otherwise stated in the text of the article) 2018. All rights reserved. No commercial use is permitted unless otherwise expressly granted.

\section{REFERENCES}

1. Beshyah SA. Fasting during the month of ramadan for people with diabetes: Medicine and fiqh united at last. IJMBS 2009;1:58-60.

2. Ghani F. Most Muslims say they fast during Ramadan. 2013. Available at http://www.pewresearch.org/fact-tank/2013/07/09/ global-median-of-93-of-muslims-say-they-fast-during-ramadan/ (accessed 4 Apr 2017).

3. Al-Arouj M, Assaad-Khalil S, Buse J, et al. Recommendations for management of diabetes during Ramadan: update 2010. Diabetes Care 2010;33:1895-902.

4. Hassanein M, Al-Arouj M, Hamdy O, et al. Diabetes and Ramadan: Practical guidelines. Diabetes Res Clin Pract 2017;126:303-16.

5. Sheikh A, Wallia S. Ramadan fasting and diabetes. BMJ 2007;335:613-4.

6. Ibrahim M, Abu Al Magd M, Annabi FA, et al. Recommendations for management of diabetes during Ramadan: update 2015. BMJ Open Diabetes Res Care 2015;3:e000108.

7. Ghouri N, Gatrad R, Sattar N, et al. Summer-winter switching of the Ramadan fasts in people with diabetes living in temperate regions. Diabet Med 2012;29:696-7.

8. Ali S, Davies MJ, Brady EM, et al. Guidelines for managing diabetes in Ramadan. Diabet Med 2016;33:1315-29.

9. Babineaux SM, Toaima D, Boye KS, et al. Multi-country retrospective observational study of the management and outcomes of patients with Type 2 diabetes during Ramadan in 2010 (CREED). Diabet Med 2015;32:819-28.

10. Salti I, Bénard E, Detournay B, et al. A population-based study of diabetes and its characteristics during the fasting month of Ramadan in 13 countries: results of the epidemiology of diabetes and Ramadan 1422/2001 (EPIDIAR) study. Diabetes Care 2004;27:2306-11.

11. Al-Houqani M, Eid HO, Abu-Zidan FM. Sleep-related collisions in United Arab Emirates. Accid Anal Prev 2013;50:1052-5.

12. Ahmedani MY, Alvi SF. Characteristics and Ramadan-specific diabetes education trends of patients with diabetes (CARE): a multinational survey (2014). Int J Clin Pract 2016;70:668-75.

13. Lee JY, Wong CP, Tan CSS, et al. Type 2 diabetes patient's perspective on Ramadan fasting: a qualitative study. BMJ Open Diabetes Res Care 2017;5:e000365.

14. Mir G, Sheikh A. 'Fasting and prayer don't concern the doctors... they don't even know what it is': communication, decision-making and perceived social relations of Pakistani Muslim patients with long-term illnesses. Ethn Health 2010;15:327-42. 
15. Cox DJ, Penberthy JK, Zrebiec J, et al. Diabetes and driving mishaps: frequency and correlations from a multinational survey. Diabetes Care 2003;26:2329-34.

16. Cox DJ, Gonder-Frederick LA, Kovatchev BP, et al. Progressive hypoglycemia's impact on driving simulation performance. Occurrence, awareness and correction. Diabetes Care 2000;23:163-70.

17. Driver and Vehicle Licensing Agency. Assessing fitness to drive: guide for medical professionals. 2018. https://www.gov.uk/ government/uploads/system/uploads/attachment data/file/596959/ assessing-fitness-to-drive-a-guide-for-medical-professionals.pdf (accessed 25 Mar 2018).

18. Directive 2006/126/EC of The European Parliament and of The Council of 20 December 2006 on driving licences (Recast). http:// eur-lex.europa.eu/LexUriServ/LexUriServ.do?uri=OJ:L:2006:403: 0018:0060:EN:PDF (accessed 25 Mar 2018).

19. Commission Directive 2009/113/EC of 25 August 2009 Amending Directive 2006/126/EC of The European Parliament and of The Council on driving licences. Official Journal of the European Union. http://eur-lex.europa.eu/LexUriServ/ LexUriServ.do?uri=OJ:L:2009: 223:0031:0035:EN:PDF (accessed 25 Mar 2018).

20. European Commission. Commission Directive (EU) 2016/1106 amending Directive 2006/126/EC of the European Parliament and of the Council on driving licences. Off J Eur Union 2016;L183:59-63 http://eur-lex.europa.eu/legal-content/EN/TXT/PDF.

21. Graveling AJ, Frier BM. Driving and diabetes: are the changes in the European Union licensing regulations fit for purpose? $\mathrm{Br} J$ Diabetes 2018;18:25-31.

22. Beshyah SA, Beshyah AS, Yaghi S, et al. A global survey of licensing restrictions for drivers with diabetes. Br J Diabetes 2017;17:3-10.

23. Driver and Vehicle Licensing Agency. VDIAB1I: report your medical condition. 2017. https://www.gov.uk/government/uploads/system/
uploads/attachment_data/file/592209/VDIAB1-medical-form.pdf (Last accessed 4-4-2017).

24. Driver and Vehicle Licensing Agency. INF188/2 - Information for drivers with diabetes treated by non-insulin medication, diet, or both 2016. https://www.gov.uk/government/uploads/system/uploads/ attachment_data/file/561792/inf188x2-information-for-drivers-withdiabetes-treated-by-non-insulin-medication-diet-or-both.pdf (Last accessed 4-4-2017).

25. Akram J, De Verga V, Ramadan Study Group. Insulin lispro (Lys(B28), Pro(B29)) in the treatment of diabetes during the fasting month of Ramadan. Diabetic Medicine 1999;16:867-74.

26. al-Kalbi IJ. al-Qawanin al-Fiqhiyyah. 119. 2nd edn. Beirut: Dar alKitab al-Arabi, 1989.

27. Zayn al-Din Ibn Nujaym. al-Ashbah wal Nadha'ir. 85. Cairo: Dar alHalabi , 1968.

28. Gatrad AR, Sheikh A. Medical ethics and Islam: principles and practice. Arch Dis Child 2001;84:72-5.

29. Kamali M. Considerations of Public Interest. Principles of Islamic Jurisprudence. Cambridge: Islamic Texts Society, 2013:352-68.

30. Abidin MI. Hashiyyah Radd al-Muhtar. . 2nd edn. Cairo: Dar alHalabi, 1966:2. 2-420.

31. Az-Zarqa', Muhammad S. Sharh al-Qawa'id al-Fiqhiyyah. 3rd edn. Damascus: Dar al-Qalam, Damascus, 1993:33-4.

32. Abu "I-Ikhlas al-Shurunbulali. Fasting. Ascent to Felicity. 1st edn. London: White Thread Press, 2010:135-8.

33. European Council for Fatwa and Research. Fatawa al-majmu'a alula. Cairo: Islamic Publishing, 1999:19-20.

34. Beshyah SA, Chatterjee S, Davies MJ. Use of SGLT2 inhibitors during Ramadan: a survey of physicians' views and practical guidance. Br J Diabetes 2016;16:20-4.

35. Chamsi-Pasha H, Albar MA. Western and Islamic bioethics: How close is the gap? Avicenna $J$ Med 2013;3:8-14. 